\title{
Initial Experience with a COVID-19 Web-Based Patient Self-assessment Tool
}

$\mathrm{J}$ Gen Intern Med 35(9):282 1-2

DOI: $10.1007 / \mathrm{s} 11606-020-05893-0$

(C) Society of General Internal Medicine 2020

\section{INTRODUCTION}

As the COVID-19 pandemic spreads, patients experiencing symptoms potentially attributable to the disease require timely assessment. As the disease burden increases, healthcare professionals may increasingly be challenged to meet the demand. Automated assessment tools - such as digital self-assessment applications-offer a potential strategy for providing guidance to patients without requiring direct attention from healthcare professionals. ${ }^{1}$ To date, several COVID-19 self-assessment tools have been released. $^{2-4}$

Our team recently developed a web-based COVID-19 selfassessment tool, available in English and Spanish, offering guidance for patients experiencing potential COVID-19 symptoms. ${ }^{2}$ Based on user input, the tool recommends medical consultation vs. home-care, and provides guidance for preventing infection spread.

In this analysis, we describe the results of almost 300,000 digital self-assessments.

\section{METHODS}

Our tool (available at: https://covidassessment.org/) was developed by a team of clinicians from the USC Gehr Center for Health Systems Science \& Innovation, in partnership with the Akido Labs health information technology partner, using information from the Centers for Disease Control and Prevention (CDC) website as a guide. The tool was initially distributed via a lay media article, $^{2}$ which led to further distribution through secondary media channels.

Web analytics software was used to track tool utilization between March 17, 2020, and April 9, 2020.

\section{RESULTS}

There were 352,257 unique users from 201 countries, of whom $78.9 \%$ accessed the tool with a mobile device. Users accessed the tool predominately from media outlets

Received April 15, 2020

Accepted April 30, 2020

Published online June 15, 2020 like STAT News and The Los Angeles Times that linked to the tool, and also via social media outlets like Facebook. Among 5,611 users who entered optional demographic data (the option to do so was added 2 weeks after the launch), $61 \%$ percent were female and the mean age was 39.

A total of 276,560 assessments were completed, and users reported symptoms potentially attributable to COVID-19 $69.6 \%$ of the time. Among those with symptoms, $80.5 \%$ reported mild or moderate symptoms that could likely be managed with home self-care, while $19.5 \%$ reported severe symptoms for which our tool recommended immediate medical attention. Of those with mild symptoms, $7.1 \%$ reported direct exposure to someone with confirmed COVID-19; for these users, our tool recommends consideration of telephone consultation with a healthcare professional to determine the need for testing.

Figure 1 shows the geographic distribution of users in the USA.

\section{DISCUSSION}

In our analysis of almost 300,000 digital self-assessments from our COVID-19 self-assessment tool, 69.6\% of users reported symptoms potentially attributable to COVID-19. Among users with symptoms, $80.5 \%$ had only mild symptoms that likely could be managed with self-care.

Importantly, we do not have data on user outcomes, and therefore, it is not possible to assess the appropriateness of our tool's recommendations, nor to determine which users actually had COVID-19. In another analysis involving 950 users of a different COVID-19 self-assessment tool embedded in a health system patient portal, the tool correctly identified 14 of 16 users who visited the emergency room within 48 hours, for a sensitivity of $87.5 \%$ (95\% CI $61.7-$ 98.5\%)."5

Another limitation of our analysis is that the study population received the tool via media sources and therefore represents a convenience sample.

Nevertheless, the widespread use of our tool highlights the willingness of the public to engage with digital health tools and self-assessment in this time of public health crisis. Future research should examine the accuracy and effectiveness of digital self-assessments among those with COVID-19 disease, as well as other uses of such technology, such as for triaging directly into telehealth or testing 


\section{COVID19 Self-Assessment Tool User Demographics}

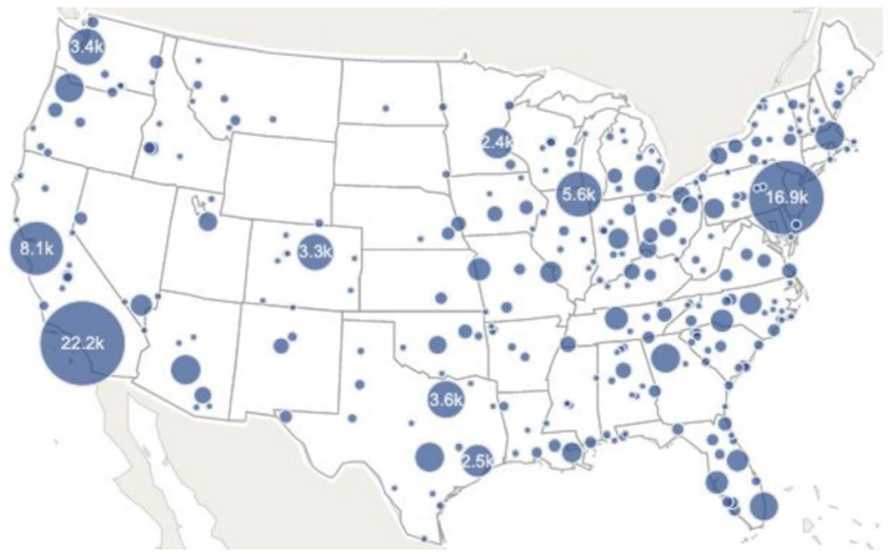

Fig. 1 COVID-19 self-assesment tool user demographics.

appointments, offering daily follow-up physical and mental health screening, and digital contact tracing. ${ }^{6}$

William M. Mehring, $B S^{1}$

Andrew Poksay, BS ${ }^{2}$

Jesse Kriege, $\mathrm{BS}^{2}$

Rithvik Prasannappa, $\mathrm{BS}^{2}$

Michael D. Wang, $M D^{3}$

Chris Hendel, MA ${ }^{4}$

Michael Hochman, MD, MPH ${ }^{4}$

${ }^{1}$ The Keck School of Medicine, University of Southern California,

Los Angeles, CA, USA

${ }^{2}$ Akido Labs, Inc,

Los Angeles, CA, USA

${ }^{3}$ Keck Medicine of USC,

Los Angeles, CA, USA

${ }^{4}$ The Gehr Center for Health Systems Science and Innovation, The Keck School of Medicine of USC, Los Angeles, CA, USA

Corresponding Author: Michael Hochman, MD, MPH; The Gehr Center for Health Systems Science and Innovation, The Keck School of Medicine of USC Los Angeles, CA, USA (e-mail: mhochman@med.usc.edu).

\section{Compliance with Ethical Standards:}

Conflict of Interest: The authors declare that they do not have a conflict of interest.

\section{REFERENCES}

1. Ting, DSw, et al. Digital Technology and COVID-19. Nat Med, 2020, https://doi.org/10.1038/s41591-020-0824-5.

2. See: https://www.statnews.com/2020/03/20/self-triage-tool-covid-19/. Accessed 2 June 2020.

3. See: https://www.apple.com/newsroom/2020/03/apple-releases-newcovid-19-app-and-websitebased-on-CDC-guidance/. Accessed 2 June 2020.

4. See: https://www.cdc.gov/coronavirus/2019-ncov/if-you-are-sick/stepswhen-sick.html. Accessed 2 June 2020.

5. Judson TJ, et al. Rapid Design and Implementation of an Integrated Patient Self-Triage and Self-Scheduling Tool for COVID-19 J Am Med Inform Assoc, 2020, ocaa051. https://doi.org/10.1093/jamia/ocaa051.

6. Ferretti L, et al. Quantifying SARS-CoV-2 Transmission Suggests Epidemic Control with Digital Contact Tracing. Science, 2020, eabb6936. https://doi.org/10.1126/science.abb6936.

Publisher's Note: Springer Nature remains neutral with regard to jurisdictional claims in published maps and institutional affiliations. 